\title{
Application of RAPD DNA fingerprinting in taxonomic identification of amphipods: a case-study with Gammarus species (Crustacea: Amphipoda)
}

\author{
Filipe O. Costa*§, Marina R. Cunha ${ }^{\dagger}$, Teresa Neuparth*, Christopher W. Theodorakis, \\ M. Helena Costa* and Lee R. Shugart ${ }^{\jmath}$ \\ *IMAR - Centro de Modelação Ecológica, DCEA, Fac. Ciência e Tecnologia, Universidade Nova de Lisboa, \\ 2829-516 Caparica, Portugal. ${ }^{\dagger}$ Departamento de Biologia, Universidade de Aveiro, 3810-193 Aveiro, Portugal. \\ ${ }^{\ddagger}$ The Institute of Environmental and Human Health, Department of Environmental Toxicology, Texas Tech University, \\ Lubbock, TX 79409-1163, USA. ${ }^{\int}$ L.R. Shugart and Associates, PO Box 5564, Oak Ridge, TN 37831, USA. \\ ${ }^{\S}$ Corresponding author, e-mail: fjc@fct.unl.pt
}

In this study randomly amplified polymorphic DNA (RAPD) fingerprinting is proposed for species identification of Gammarus, based on the electrophoretic position of amplified DNA bands. Three common marine amphipods of European estuaries - G. chevreuxi, G. insensibilis and G. locusta - were profiled using ten RAPD primers, accompanied by a careful morphological identification. Nine of these primers produced a very distinct species-specific RAPD profile, allowing unambiguous differentiation of amphipod species assayed. The RAPD fingerprints were here characterized by 8-12 amplicons for each primer. Each amplicon was visualized as a band of known molecular length, with characteristic band thickness and density. A total of 78 diagnostic bands, based on the most robust and evident amplicons found for each primer and species, are proposed for identification of the Gammarus species analysed. These results allowed us to identify an unknown amphipod species from a previous study as $G$. insensibilis, only based on the RAPD fingerprint. One primer was sufficient for this identification. A taxonomic identification system integrating molecular and morphological tools is proposed for Gammarus.

\section{INTRODUCTION}

Taxonomic identification of amphipod species (Amphipoda, Crustacea) is a complex process that frequently requires a great deal of expertise. The taxonomy of the genus Gammarus is one of the most problematic among the Amphipoda and has been historically immersed in uncertainty and dispute. Meyran et al. (1997) summarized the problems encountered by European freshwater Gammarus taxonomy. These problems are similar to a great extent to those involving European marine Gammarus, which have been addressed by other authors (Stock, 1967; Bulnheim \& Scholl, 1980; Skadsheim \& Siegismund, 1986). Morphology-based identification of Gammarus requires the examination of numerous characters, some of which are difficult to observe, and may display a considerable amount of intraspecific variation (Meyran et al., 1997). In addition, there are also ontogenetic variations and sex differences, which are not always considered in most taxonomic keys, primarily based on adult males. All of these facts contribute to hinder the establishment of diagnostic morphological criteria to distinguish Gammarus species, which led Pinkster (1983) to question the value of these characters in the taxonomy of Gammarus. Nevertheless, the morphologybased identification is still the most widely used approach and therefore rigorous identification of Gammarus continues to be problematic for many researchers and almost inaccessible for those less familiar with amphipod taxonomy. As a consequence, a large amount of relevant information regarding the diversity, distribution and ecology of Gammarus species has been lost, and this will continue unless new approaches are developed.
Complementary and/or alternative methodologies to the conventional morphology-based taxonomic identification of amphipod species are therefore urgently required, especially techniques that can be used routinely providing a simple and universal application. The randomly amplified polymorphic DNA (RAPD) technique presents advantages such as the large number of loci that can be screened without prior knowledge of genome sequences, the rapidity of the procedure, the large number of samples that can be processed simultaneously and the low amounts of specimen tissue required. In addition, the extracted DNA can be archived, and reanalysed using RAPD or other molecular biology techniques. Another valuable feature of RAPDs is that, in contrast to morphology or allozyme based approaches, RAPDs provide consistent markers that are physiologically independent and can be applied in species discrimination for any ontogenic stage, starting from the embryo.

RAPDs have also been used to analyse intraspecific genetic differentiation of Gammarus locusta L. populations of the Portuguese coast (F.O. Costa et al., unpublished). It was following this study, that our attention has focused on a number of specimens from the most southern sampling site (Ria de Alvor) that showed a very distinctive banding pattern, therefore indicating the presence of another species co-inhabiting with $G$. locusta in that location. In the Portuguese coast taxonomic difficulties arise from the presence of a mixed fauna of Gammarus spp., where species from northern Europe and from the Mediterranean may show overlapping distributions and for which there is not a common taxonomic key. In addition to $G$. locusta, the species Gammarus insensibilis 
Stock, 1966, Gammarus crinicornis Stock, 1966, Gammarus aequicauda (Martynov, 1931) and Gammarus chevreuxi Sexton, 1913 also occur here (Marques, 1989). We intend to depart from this case study to explore the potential of RAPD fingerprinting to identify amphipod species, by determining tentative species-specific markers that may be applied universally to distinguish these amphipods. We selected for this purpose the three most common marine Gammarus spp. occurring on the Portuguese coast: G. chevreuxi, G. insensibilis and G. locusta (Marques, 1989), plus two other gammaridean species-Melita palmata (Montagu) and Gammarella fucicolla (Leach). The two latter amphipods are unequivocally distinct species from the Gammarus spp., and were used as a positive control for the discriminatory ability of the technique, and granting additional evidence for the viability of generalized application of RAPDs in amphipods' taxonomic identification. Careful morphological identification was applied simultaneously as a validation system for the resultant molecular markers. Finally, we have tested the molecular markers proposed to identify the Gammarus species that produced the unknown RAPD profiles observed in specimens collected from Ria de Alvor.

\section{MATERIALS AND METHODS \\ Amphipod collection and processing}

Amphipods were collected in May 2001 from several coastal systems of the Portuguese coast. Gammarus locusta and Gammarella fucicolla were collected among macroalgae in the south margin of the Sado estuary $\left(38^{\circ} 30^{\prime} \mathrm{N} 8^{\circ} 54^{\prime} \mathrm{W}\right)$. Two other populations of Gammarus locusta were collected in the coastal lagoons of Foz do Arelho $\left(39^{\circ} 10^{\prime} \mathrm{N} 9^{\circ} 14^{\prime} \mathrm{W}\right)$ and Ria de Alvor $\left(37^{\circ} 8^{\prime} \mathrm{N} 8^{\circ} 37^{\prime} \mathrm{W}\right)$. Specimens of $G$. insensibilis and Melita palmata were collected in the Sado estuary saltpans $\left(38^{\circ} 26^{\prime} \mathrm{N} 8^{\circ} 43^{\prime} \mathrm{W}\right)$, upstream from where G. locusta and Gammarella fucicolla were sampled. Gammarus chevreuxi was collected in the upper reaches of Canal de Mira-Ria de Aveiro $\left(40^{\circ} 31^{\prime} \mathrm{N} 8^{\circ} 45^{\prime} \mathrm{W}\right)$. In addition, one sole specimen of G. crinicornis, occasionally found covered by a fragment of Ulva sp. laying on the sand in the Areias Brancas beachSanto André, was also included in this study $\left(38^{\circ} 01^{\prime} \mathrm{N}\right.$ $\left.8^{\circ} 47^{\prime} \mathrm{W}\right)$.

The amphipods were brought alive to the laboratory and inspected for species identification under a stereomicroscope. Eight adult specimens from each species were selected, including equal number of males and females, except for $G$. chevreuxi for which only males were found and G. crinicornis for which only one male was available. The material examined is listed below (the codes in brackets are used in Table 1 and figures to identify the specimens): Gammarus locusta: 2 males (L1, L2) and 2 females (L5, L6) from the Sado estuary; 1 male (L3) and 1 female (L7) from Foz do Arelho; 1 male (L4) and 1 female from Ria de Alvor (L8). Gammarus insensibilis: 4 males (I1-I4) and 4 females (I5-I8). Gammarus chevreuxi: 8 males (Cl-C8). Gammarus crinicornis: 1 male (Crl). In addition to these amphipods, RAPD fingerprints obtained in a previous study (F.O. Costa et al., unpublished) were also analysed. They comprised profiles of about 20 specimens of $G$. locusta from each of the coastal ecosystems (Ria de Aveiro, Sado estuary, Foz do Arelho and Ria de Alvor) and ten other profiles of an unknown Gammarus sp. from Ria de Alvor, all of them collected in September 2000.

Table 1. Morphological characteristics of the Gammarus specimens examined: head length in mm (HL); number of articles in the accessory flagellum (AAF) of antenna 1 (A1); number of setal groups on the posterior margin (SGPM) of gnathopods 1 and 2 (G1, G2); number of setules (Set) on the distal margin of epimeral plates 2 and 3 (EP2, EP3); length-width ratio (L/W) of coxal plate 4 (CP4) and basis of pereopod 7 (BP7); length ratio of outer and inner rami (OR/IR) of uropod 3 (U3). Values in bold drawn from literature (Stock, 1967; Lincoln, 1979; Karaman, 1982).

\begin{tabular}{|c|c|c|c|c|c|c|c|c|c|c|c|}
\hline Specimen & & Sex & $\begin{array}{c}\mathbf{H L} \\
(\mathrm{mm})\end{array}$ & $\begin{array}{c}\text { A1 } \\
(\mathrm{AAF})\end{array}$ & $\begin{array}{c}\text { G1 } \\
(\mathrm{SGPM})\end{array}$ & $\begin{array}{c}\text { G2 } \\
(\mathrm{SGPM})\end{array}$ & $\begin{array}{l}\text { EP2 } \\
\text { (Set) }\end{array}$ & $\begin{array}{l}\text { EP3 } \\
\text { (Set) }\end{array}$ & $\begin{array}{c}\text { GP4 } \\
(\mathrm{L} / \mathrm{W})\end{array}$ & $\begin{array}{c}\text { BP7 } \\
(\mathrm{L} / \mathrm{W})\end{array}$ & $\begin{array}{c}\text { U3 } \\
(\mathrm{OR} / \mathrm{IR})\end{array}$ \\
\hline \multirow[t]{9}{*}{ G. locusta } & & & & $8-15$ & & $6-8$ & several & several & & $<1.5$ & $0.9-1.0$ \\
\hline & L1 & M & 2.02 & $11 ; 11$ & $6 ; 5$ & $10 ; 10$ & - & $5 ; 6$ & 1.05 & 1.57 & 0.97 \\
\hline & L2 & $\mathrm{M}$ & 2.06 & $12 ; 12$ & $6 ; 5$ & $13 ; 12$ & - & $5 ; 6$ & 1.02 & 1.49 & 0.97 \\
\hline & L3 & $\mathrm{M}$ & 1.90 & $11 ; 11$ & $6 ; 6$ & $11 ; 11$ & - & $1 ; 3$ & 1.02 & 1.51 & 0.97 \\
\hline & $\mathrm{L} 4$ & $\mathrm{M}$ & 1.80 & $9 ; 9$ & $6 ; 6$ & $11 ; 11$ & - & $4 ; 7$ & 1.04 & 1.51 & 0.92 \\
\hline & L5 & $\mathrm{F}$ & 1.30 & $7 ; 7$ & $5 ; 5$ & $-; 7$ & - & $6 ; 6$ & 1.17 & 1.44 & - \\
\hline & L6 & $\mathrm{F}$ & 1.72 & $11 ; 9$ & $5 ; 5$ & $-; 8$ & - & $10 ; 16$ & 1.12 & 1.45 & 0.95 \\
\hline & L7 & $\mathrm{F}$ & 1.28 & $-; 8$ & $4 ; 5$ & $7 ;-$ & $3 ; 7$ & $3 ; 3$ & 1.08 & 1.33 & 0.90 \\
\hline & L8 & $\mathrm{F}$ & 1.86 & $11 ; 11$ & $5 ; 5$ & $8 ; 8$ & $30+$ & $20+$ & 1.07 & 1.48 & 0.94 \\
\hline \multirow[t]{5}{*}{ G. insensibilis } & & & & $7-12$ & & $3-5$ & $2-3$ & $0-1$ & & $1.7-2.0$ & $0.8-0.9$ \\
\hline & $\mathrm{I} 1$ & $\mathrm{M}$ & 1.40 & $-; 9$ & $4 ; 4$ & $7 ; 7$ & - & $1 ; 1$ & 1.05 & 1.74 & 0.76 \\
\hline & I2 & $\mathrm{M}$ & 1.44 & $7 ; 7$ & $4 ; 4$ & $8 ; 8$ & - & $1 ; 1$ & 1.06 & 1.72 & 0.78 \\
\hline & I5 & $\mathrm{F}$ & 1.44 & $6 ; 5$ & $5 ; 3$ & $4 ;-$ & - & $1 ; 1$ & 1.37 & 1.72 & 0.74 \\
\hline & I6 & $\mathrm{F}$ & 1.34 & $-;-$ & $6 ; 6$ & $5 ;-$ & - & - & 1.20 & - & 0.78 \\
\hline \multirow[t]{3}{*}{ G. chevreuxi } & & & & $6-7$ & & & $1-2$ & $1-2$ & & & $0.5-0.7$ \\
\hline & $\mathrm{C} 1$ & $\mathrm{M}$ & 1.12 & $6 ;-$ & $4 ; 4$ & $8 ; 8$ & - & $2 ; 2$ & 1.17 & 1.68 & 0.61 \\
\hline & $\mathrm{C} 2$ & M & 1.18 & $6 ; 6$ & $5 ; 4$ & $7 ; 7$ & - & $2 ; 2$ & 1.11 & 1.56 & 0.52 \\
\hline \multirow[t]{2}{*}{ G. crinicornis } & & & & $8-12 *$ & & $5-7$ & several & $0-1$ & & $\sim 1.3$ & \\
\hline & Crl & M & 1.34 & $7 ; 7$ & $5 ; 5$ & $-; 8$ & - & $1 ; 1$ & 1.00 & 1.26 & 0.85 \\
\hline
\end{tabular}

*, 4-6 in specimens from the Mediterranean. 


\section{Morphological analysis}

Fifteen specimens of the four selected Gammarus species from the list above were examined for morphological characterization. The analysis focused on traits considered diagnostically important by Stock (1967), Lincoln (1979) and Karaman (1982). These traits are located in the head and antennae, gnathopods 1 and 2, pereopods 4 and 7, epimeral plates 2 and 3, urosome, uropod 3 and telson.

The anterior and posterior parts of the body were cut off using ophthalmologic scissors, pereopods 4 and 7 were also isolated and the rest of the body provided enough material for genetic analysis. The isolated parts of each specimen were preserved in $70 \%$ ethanol and further examined and photographed using bright field. This procedure permits retention, for some selected specimens, of a genetic archive and the corresponding morphological archive that includes not the whole specimen but only the diagnostically important features. Both the genetic archive and the preserved parts can be used for future reference and comparative studies.

\section{RAPD protocol}

The remaining body parts of the amphipods were homogenized in a $1.5 \mathrm{ml}$ microtube containing $500 \mu \mathrm{l}$ TEN (50 mM Tris, $2.5 \mathrm{mM}$ EDTA and $100 \mathrm{mM} \mathrm{NaCl}$ ). Following addition and mixing with $50 \mu \mathrm{l}$ of $10 \%$ sarcosyl, the resultant solution was extracted twice with PCI (phenol:chloroform:isoamyl alcohol, 25:24:1, v/v/v). The extracts were digested with ribonuclease $\mathrm{A}$ and proteinase $\mathrm{K}$ for 1 and $2 \mathrm{~h}$ at $55^{\circ} \mathrm{C}$ water bath, respectively. The DNA was precipitated from the aqueous phase with ethanol, and resuspended in TE $(10 \mathrm{mM}$ Tris and $1 \mathrm{mM}$ EDTA, pH 8.0). Randomly primed amplifications were performed in a final volume of $12.5 \mu \mathrm{l}$, containing $0.25 \mathrm{mM}$ of each dNTP, $1 \mathrm{U}$ of Taq DNA polymerase, $1 \times$ PCR buffer $(20 \mathrm{mM}$ Tris- $\mathrm{HCl}-\mathrm{pH}$ 8.4, $50 \mathrm{mM} \mathrm{KCl})$, $3.5 \mathrm{mM} \mathrm{MgCl}_{2}$ (all reagents Invitrogen ${ }^{\mathrm{TM}}$ ), $0.8 \mu \mathrm{M}$ of primer, and two distinct amounts of template DNA of the same individual (20 and $1.12 \mathrm{ng}$ ). The primers used and respective nucleotide sequences were as follows: OPA2 (5'-TGCGGAGCTG-3'), OPA9 (5'-GGGTAACGCG-3'), OPA10 (5'-GTGATCGCAG-3'), OPAl6 (5'AGCGAGCGAA- $\left.3^{\prime}\right)$, OPB7 (5'-GGTGACGCAG-3'), OPD2 (5'-GGACCCAACC-3 $\left.3^{\prime}\right)$ OPD3 (5'GTCGCCGTCA-3'), OPD7 (5'-TTGGCACGGG-3'), 4XGACA (5'-GACAGACAGACAGACA-3'), M13 (5'GTAAAACGACGGCCAGT-3'). All primers were purchased from Operon Technologies ${ }^{\mathrm{TM}}$, except M13 and 4XGACA that were prepared by MWG Biotech $^{\mathrm{TM}}$. Amplifications were conducted in a thermocycler iCycler $\left(\right.$ BioRad $\left.^{\mathrm{TM}}\right)$ consisting of an initial denaturation at $95^{\circ} \mathrm{C}$ for $5 \mathrm{~min}$ followed by 40 cycles of amplification (denaturing $93^{\circ} \mathrm{C}-40 \mathrm{~s}$, annealing $55^{\circ} \mathrm{C}-60 \mathrm{~s}$ and extension $72^{\circ} \mathrm{C}-60 \mathrm{~s}$ ) and a final extension of $6 \mathrm{~min}$ at $72^{\circ} \mathrm{C}$. The amplification products were maintained at $4^{\circ} \mathrm{C}$ until loaded onto the gels.

Electrophoresis was conducted in $2.5 \%$ agarose gels in TAE buffer (40 mM Tris- $\mathrm{pH}$ 7.6, $20 \mathrm{mM}$ acetic acid and $1 \mathrm{mM}$ EDTA) run at 90 volts for $2.5 \mathrm{~h}$, followed by staining with ethidium bromide. Ten microlitres of PCR products of the same individual, originated from two independent PCR reactions, were allocated side by side on the gel, to verify band consistence. Molecular size standards consisting of 100 base pair ladders (Invitrogen ${ }^{\mathrm{TM}}$ ) were run in lanes flanking groups of about 20 samples and one negative control in each gel.

Each RAPD-DNA profile was scored twice, independently. Bands that were not clear and unequivocal or were not consistent between replicate PCR amplifications were not considered for further analysis. After robust bands (amplicons) were assigned to each primer (and species), a matrix of presence (1) vs absence (0) of the selected bands was built for each primer (and species). Band frequency percentages $(\mathrm{BF} \%=$ number of individuals with the band/total number of individuals scored $\times 100$ ) were determined for each species/primer. The amplicons were also observed regarding their thickness, optical density, and robustness. These features were considered to empirically select diagnostic bands for each species and primer. High quality bands, displaying a robust amplification, occurring in most of the individuals [Band frequency $(\mathrm{BF})>90 \%$ ] and which are more easily detectable and scored are indicated as tentative diagnostic species markers.

The robustness of the DNA fingerprints obtained were tested by comparing RAPD fingerprints of $G$. locusta from the present study with the fingerprints of $G$. locusta obtained in the previous study (F.O. Costa et al., unpublished). Given the concordance of the species-specific markers of $G$. locusta obtained from the two independent studies using distinct stocks of individuals, the results for this species were pooled.

\section{RESULTS}

\section{Morphological analysis}

Adult males of the four species of Gammarus examined can be readily distinguished by using only two features: (a) the presence of calceoli on the flagellum of antenna 2 (G. locusta; G. crinicornis); (b) the presence of prominent angular humps on the dorsal margin of the urosome (G. locusta; G. insensibilis). Additionally, G. chevreuxi can be easily recognized by the presence of long, fine and characteristically curled setae on antenna 2, gnathopods 1 and 2, pereopod 3 and uropod 3, and G. crinicornis by its characteristic antenna 2 with a short flagellum (up to only about 12 articles) and dense transverse rows of setae (curved distally) on peduncle articles 4 and 5 (Figure 1A,B).

Distinctive sexual secondary characters make it relatively easy to ascribe males to the appropriate species, but females and especially juveniles do not present such characters and are usually much more difficult to identify. In general, the specimens closely matched the diagnosis given by Stock (1967), Lincoln (1979) and Karaman (1982) with some variations in setation (especially within the $G$. locusta specimens). The females of $G$. insensibilis showed an emarginate distal margin of coxal plate 4 that is not mentioned by these authors.

Table 1 shows the results of the morphological analysis and the most important traits used to characterize the different species. An effort was made to choose objective and quantitative characters (e.g. counts, biometric ratios) because qualitative criteria (e.g. shape differences, gradations) are always associated with a certain subjectivity often allied to confusion due to different terminology used by different authors. 


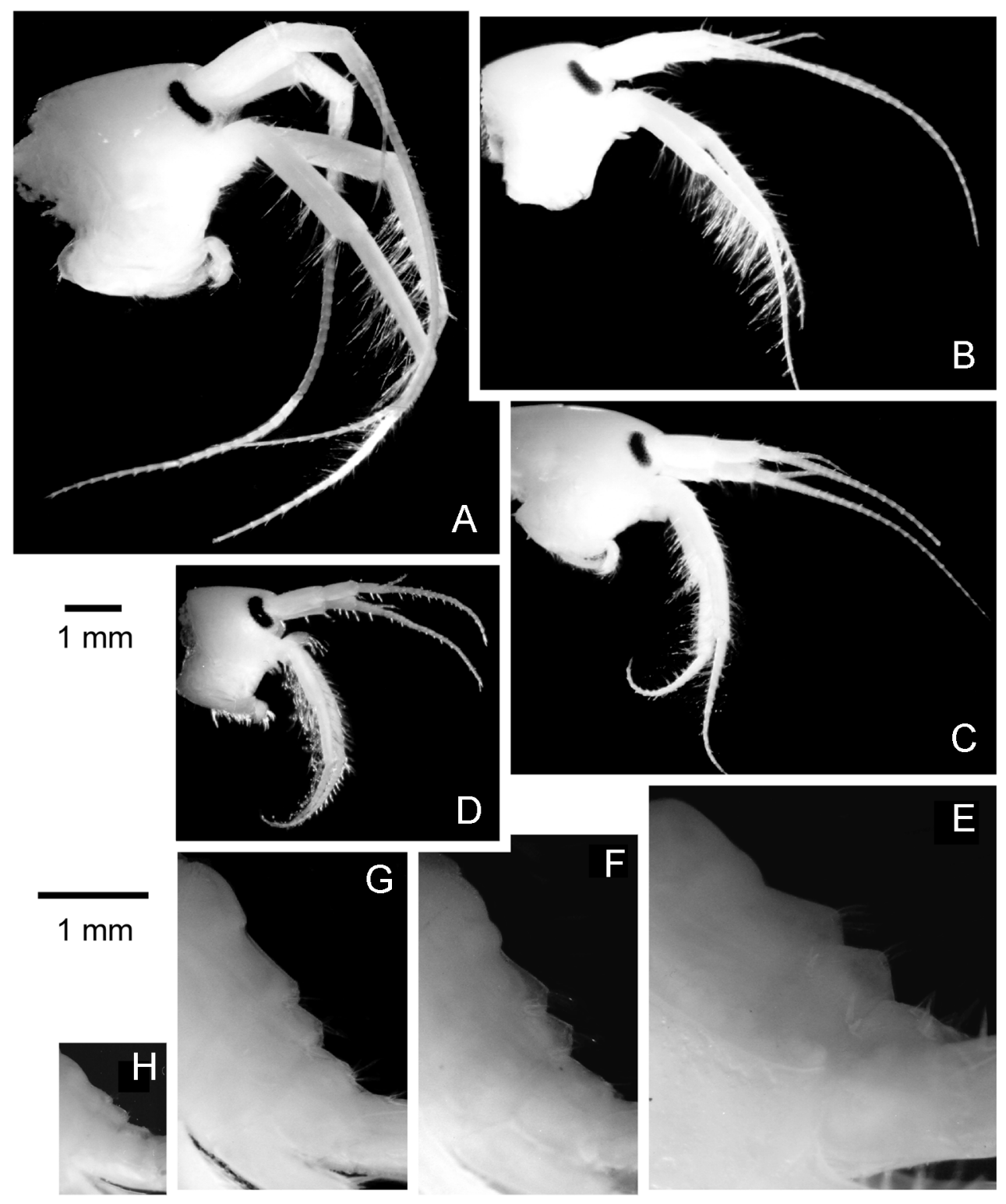

Figure 1A. Bright field microscopy photographs of morphological diagnostic characters for taxonomic identification of Gammarus analysed in this study. Head: (A) G. locusta; (B) G. insensibilis; (C) G. crinicornis; (D) G. chevreuxi. Urosome: (E) G. locusta; (F) G. insensibilis; (G) G. crinicornis; $(\mathrm{H})$ G. cheoreuxi.

Even with a rather small number of specimens it is possible to assume that some of the selected traits show a considerable amount of variation that may be related to the gender and/or size of the specimens. This is the case, for instance, of the number or articles in the accessory flagellum of antenna 1 , the number of setal groups on the posterior margin of gnathopods and the length/width ratio of coxal plate 4 .

The most interesting and reliable trait for taxonomical discrimination appears to be the length relation between the outer and inner rami of uropod 3, which permits a clear differentiation between the species considered. It is relatively easy to assess and showed values in agreement with the literature: $0.90-0.97$ for G. locusta, 0.74-0.78 for $G$. insensibilis, $0.52-0.61$ for $G$. chevreuxi and 0.85 for G. crinicornis (Table 1).

The length/width ratio of the basis of pereopod 7 also seems to be a fairly consistent trait, but the differences among species are not so marked as in the previous example. Another useful trait is the number of setules on the distal margin of the epimeral plates with the advantage that this part of the animals is almost always well preserved while the uropods and pereopods are frequently lost or damaged. The number of setules showed large variations in the examined specimens of $G$. locusta. Variations in setation may be due to intraspecific differences between populations of different locations and this issue should be further investigated in future studies.

The three above mentioned traits should always be considered together to allow an accurate morphological identification of the species considered. They are valid both for males and females. Future studies are required to assess intraspecific variations among populations and validate these criteria for juvenile specimens.

\section{RAPD DNA fingerprints}

The PGR conditions used generally produced robust RAPD fingerprints, which were characterized by a 


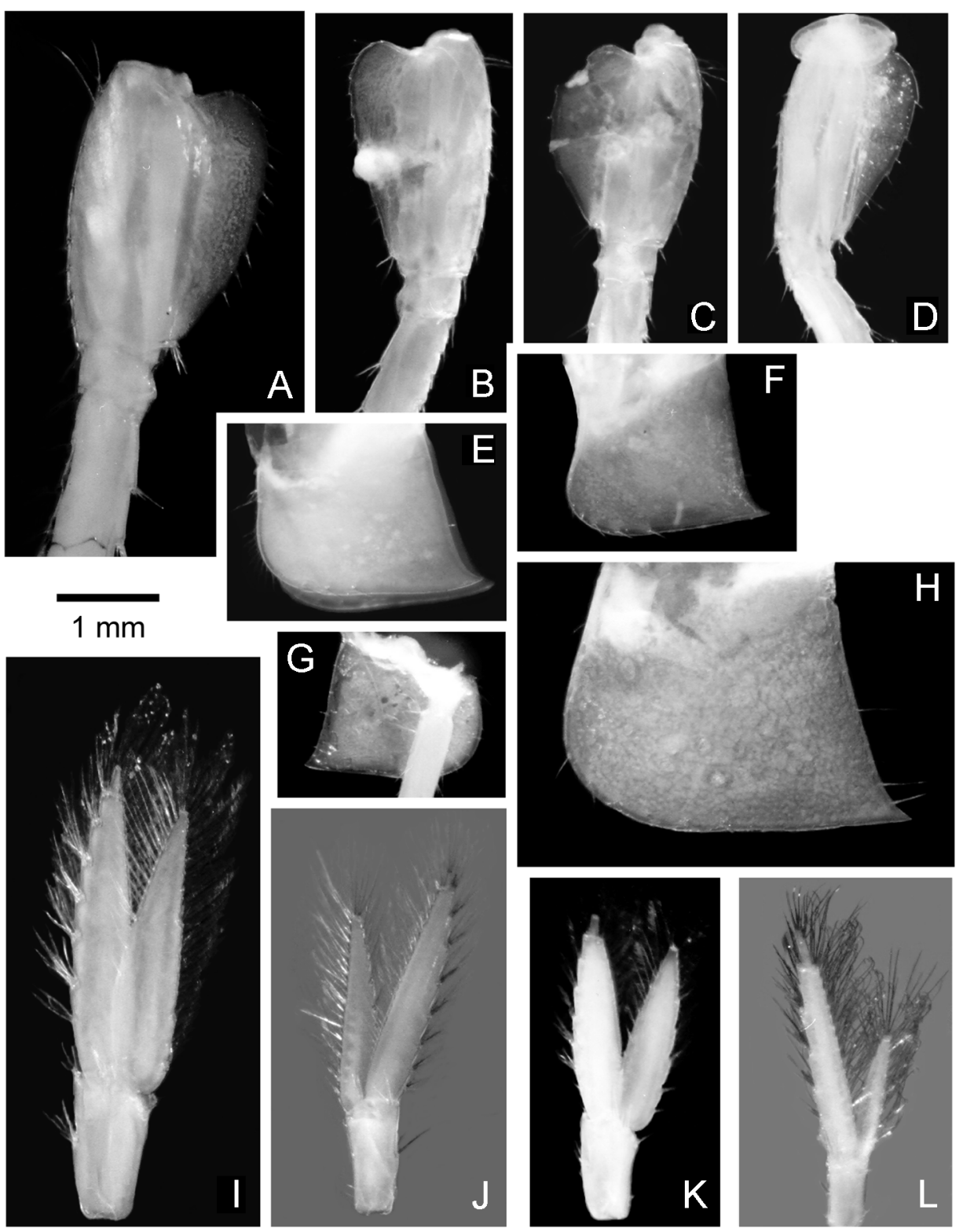

Figure 1B. Bright field microscopy photographs of morphological diagnostic characters for taxonomic identification of Gammarus spp. analysed in this study. Basis of pereopod 7: (A) G. locusta; (B) G. insensibilis; (C) G. crinicornis; (D) G. chevreuxi. Epimeral plate 3: (E) G. crinicornis; (F) G. insensibilis; (G) G. chevreuxi; (H) G. locusta. Uropod 3: (I) G. locusta; (J) G. insensibilis; (K) G. crinicornis; (L) G. chevreuxi.

particular banding pattern for each species and primer. The amplicons obtained using the primer OPAl6 showed considerable variation and were not as robust and clear as those obtained with the remaining primers. For this reason the data provided with this primer were not considered equally eligible for species identification and were not used further. For the other nine primers, there were sets of bands that were unique to each species, although all species-specific bands were not present in all individuals within a species. A low and variable number of surplus bands were observed in negative controls, but were eliminated with the addition of template DNA. The RAPD profiles of each species were independent of the negative control bands. No particular genus-characteristic RAPD profiles were detected when Gammarus species were compared with the remaining amphipod species. Like the profiles of Gammarus spp., the positive controls of Melita palmata and Gammarella fucicolla also displayed their own specific banding patterns, although fingerprints of $M$. palmata were usually of poorer quality, showing less and more variable bands. Within each species no sex-specific bands were observed.

The number of amplicons produced varied with primer and species, and therefore among the Gammarus only eight to 12 bands were selected in each case to characterize the RAPD profile. Although G. crinicornis showed a distinctive profile for every primer tested, no band selection was carried out since only one specimen was analysed. Figure 2 shows representative images of each of the profiles of $G$. locusta, G. insensibilis and $G$. chevreuxi for four primers selected among the nine eligible primers. Each set of images is accompanied by a schematic display of the RAPD fingerprint, comprising the selected bands together with their frequencies, and molecular sizes, along with an indication of the diagnostic bands. 

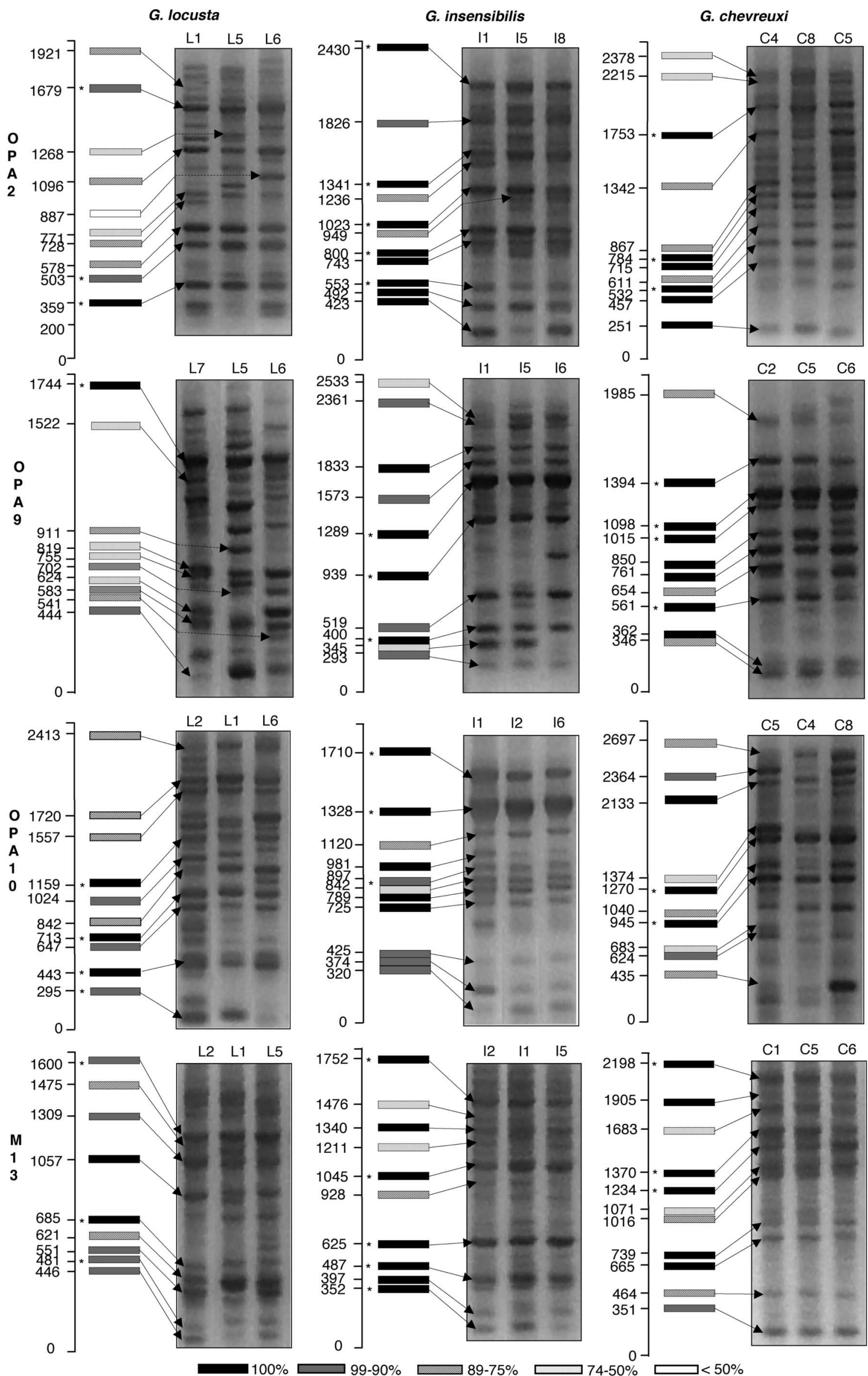

Figure 2. Schematic display of RAPD banding patterns obtained for Gammarus locusta, G. insensiblis and G. chevreuxi, with primers OPA2, OPA9, OPA10 and M13. Indicative molecular size in base pairs (bp) are presented for each amplicon. L1-8, I1-8 and C1-9 are sample labels for G. locusta, G. insensiblis and G. chevreuxi respectively. Asterisk (*) indicates diagnostic band. 
A total of 78 diagnostic bands was selected to identify these Gammarus, 23 for G. locusta, 29 for G. insensibilis and 26 for $G$. chevreuxi. The quality and efficiency of each primer to distinguish Gammarus differed. The primers OPA10 and OPA9 gave a reliable and clear discrimination for the three species. The primer 4xGACA was also very efficient in species distinction, showing fewer but very robust bands. To identify $G$. locusta the primers OPD7, 4xGACA and OPA9 provide evident diagnostic bands, whereas for G. chevreuxi OPA9, M13 and OPD2 are more appropriate. For $G$. insensibilis the primers OPA10, OPA9 and OPB7 show remarkably clear diagnostic bands.

Based on the above information it was possible to identify all of the unknown Gammarus sp. specimens from Ria de Alvor as G. insensibilis. A 100\% match was obtained when the diagnostic bands were scored. Identification was possible with any one of the nine primers discussed above, although the whole nine-primer set was used for confirmation. The amphipods identified by this approach as G. insensibilis were ten, out of 29 from Ria de Alvor fingerprinted by F.O. Costa et al. (unpublished). It can be concluded therefore that, regarding adult males, this sample was composed of about two thirds G. locusta and one third $G$. insensibilis.

\section{DISCUSSION}

Here we propose a molecular approach for phenetic species identification of some Gammarus strictly based on the electrophoretic position of amplified DNA bands. The RAPD profiles obtained in this study were totally concordant with the morphology-based taxonomical identification. Nine out of ten primers used produced a very distinct species-specific RAPD profile, allowing us to unambiguously differentiate the amphipod species assayed with a simple observation of the RAPD fingerprint. Each amphipod species bears a unique banding pattern for each primer. Seventy eight tentative diagnostic bands were found, based on the most robust and clear bands found for each primer and Gammarus species tested. The distinctiveness of the profiles obtained for Melita palmata and Gammarella fucicolla indicate that this approach may be useful for other amphipod genera than Gammarus.

Our results allowed us to identify the unknown amphipod species that was detected in a previous study as $G$. insensibilis, only based on the RAPD fingerprint. In this case one primer was sufficient to identify the amphipod species, although the whole primer set was used for confirmation. In 29 randomly sampled Gammarus from Ria de Alvor, ten were found to be $G$. insensibilis and the remaining G. locusta. These Gammarus have been found in Portugal usually inhabiting distinct areas of estuarine ecosystems such as the Sado estuary or the Ria de Aveiro. Gammarus locusta is usually found at higher salinities than $G$. insensibilis but some overlap may occur in the contact area of their distributions. If future studies confirm the co-inhabitance of these two Gammarus in Ria de Alvor, a number of questions can be raised regarding the reasons for this unusual overlapping distribution in Ria de Alvor and concerning the ecological consequences for both species, for instance in what relates with interspecific competition and the eventual occurrence of interspecific matings and hybrids (e.g. Kolding, 1986; Dick \& Elwood, 1992).

As opposed to Gammarus species from northern Europe, especially from the Gammarus zaddachi complex that were submitted to diverse allozyme studies (Bulnheim \& Scholl, 1980; Skadsheim \& Siegismund, 1986), the primarily Mediterranean G. locusta complex, remains almost untouched since Stock's (1967) taxonomic revision. Given the morphological complexity of the $G$. locusta group, it would be worth determining additional taxonomic criteria to back up morphological identification. A recent review of allozyme studies in amphipods suggests that current taxonomic inventories may be considerably underestimated for these crustaceans (Hogg et al., 1999). The freshwater amphipod Hyalella azteca s.l. is one good example in which genetic data has repeatedly identified a complex of cryptic species (Hogg et al., 1998; Witt \& Hebert, 2000). In the most recent of these studies, combined allozyme and mitochondrial cytochrome c oxidase I gene data revealed a complex of at least seven species, showing marked genetic, but little morphological difference (Witt \& Hebert, 2000). Hogg et al. (1999) advocate a taxonomic re-evaluation of aquatic amphipods, including molecular techniques, and also mantain that genetic monitoring should become standard practice in field biodiversity surveys of invertebrates.

The main difficulty regarding the application of genetic data in taxonomy is that there are neither generally accepted practical procedures nor any established consensus (Westheide \& Hass-Cordes, 2001). Benecke (1998) maintains that it would be worth developing a universal scoring system for RAPD typing with regard to taxonomic identification of forensic insect species. This author considers that definitive insect identification is not possible at present, namely because it would require databases that are not currently available and would need to be created for a large number of species, and because of potential incompatibility between laboratories results. In fact, although it is not currently feasible for insects, which represent more than $80 \%$ of all species diversity (Benecke, 1998), it may be possible for Gammarus amphipods, that comprise 120 species, of which 105 are freshwater species and 15 brackish or marine (Karaman \& Pinkster, 1977; Barnard \& Karaman, 1991).

The combination of morphological data with RAPD fingerprints, on the other hand, appears to be quite feasible for Gammarus as it is demonstrated in this study. Here we propose a procedure in which morphological and genetic diagnostic features can be obtained from the same specimen. It is anticipated that, if the RAPD diagnostic bands are universal species-specific markers, they should be found in any individual of the same species, regardless of sex, provided that the same analytical conditions are applied. Therefore we have named the diagnostic markers as 'tentative', since they require further validation in future studies, namely by analysing specimens from other regions, preferably comprising the entire distribution range, by conducting inter-laboratory calibration and by testing these markers in species complexes, cryptic species and hybrids. A number of actions can be performed using recent technologies to develop a new combined taxonomic identification system for Gammarus integrating RAPDs and other molecular tools. It may include: 
1. Definition of standardized procedures for conducting RAPD analysis for taxonomic differentiation of species. Introducing quality control protocols, including positive and negative controls and reference samples, and defining pre-filtering of the profiles. Variability due to pippeting may be greatly reduced using standardized materials, as for example with 'Ready-to-go beads ${ }^{\circledR}$ ', in which individual PCR-tubes comprising all necessary reagents for RAPD analysis (except template DNA) are provided (Benecke, 1998; Tseng et al., 2001). Moreover, automated systems and specialized software can be of great assistance in the analysis and characterization of RAPD fingerprints (Benecke, 1998; Tseng et al., 2001).

2. Creation of a library of RAPD profiles and speciesspecific molecular markers of Gammarus spp., supported by a previous morphological identification which in turn must be validated by photographs of the most relevant morphological features. Advantage of the photographs is that they can be easily available to everyone.

3. The preserved parts of the specimens (head with appendages, gnathopods 1 and 2, pereopods 4 and 7, and posterior end including epimeral plate 3) should be archived in Museum collections following a procedure similar to that of the deposition of type specimens. In case of description of new species based on RAPD fingerprinting, the deposited parts of the reference specimen (holotype) should be accompanied by the deposition of syntypes (whole specimens), as usual.

4. Archiving of DNA extracts from reference individuals, preferably those that were photographed. A well-known advantage of this system is that archived samples can be re-assayed at any time in any laboratory, thus providing a very useful experimental control.

5. When further confirmation is required, RAPD analysis can also be complemented by other molecular techniques (e.g. Hannafi et al., 2001; Westheide \& HassCordes, 2001). If no other means are available at the time of RAPD analysis, species differentiation can be validated in the future by applying other molecular techniques to archived samples.

6. Finally, all the taxonomical information derived from different sources - location of preserved parts, morphological description, photographs, RAPD profiles and other molecular data - can be integrated in a databank of Gammarus taxonomy and made available worldwide via the internet.

It is the authors intention that the methodology here proposed may be a starting point for the development of such a system for assisting taxonomic identification of Gammarus spp. and eventually other amphipod species.

We are thankful to Professor Isabel Spencer for making available the gel photographing system and Dr Mario João Gadanho for proposing PCR protocol and some primers. This work was supported by research grant PRAXIS/P/BIA/10225/98 and fellowships BD/11575/97 and BD/21613/99 from 'Fundação para a Ciência e Tecnologia'.

\section{REFERENCES}

Barnard, J.L. \& Karaman, G.S., 1991. The families and genera of marine gammaridean Amphipoda (except marine gammaroids). Records of the Australian Museum, 13, Supplement 1, 1-417.
Benecke, M., 1998. Random amplified polymorphic DNA (RAPD) typing of necrophageous insects (diptera, coleoptera) in criminal forensic studies: validation and use in practice. Forensic Science International, 98, 157-168.

Bulnheim, H.P. \& Scholl, A., 1980. Evidence of genetic divergence between two brackish-water Gammaridean sibling species. Marine Ecology Progress Series, 3, 163-165.

Dick, J.T.A. \& Elwood, R.W., 1992. Coexistence and exclusion among Gammarus species: behavioural avoidance of interspecific precopulation by male G. pulex (Amphipoda). Oikos, 64, 541-547.

Hannafi, R., Barhoumi, M., Ali, S.M. \& Guizani, I., 2001. Molecular analysis of Old World Leishmania RAPD markers and development of PCR assay selective for parasites of the L. donovani species complex. Experimental Parasitology, 98, 90-99.

Hogg, I.D., Eadie, J.M. \& Lafontaine, Y., 1999. Passive dispersal among fragmented habitats: the population genetic consequences for freshwater and estuarine amphipods. In Crustaceans and the biodiversity crisis (ed. E.R. Schram and J.C. von Vaupel Klein), pp. 307-326. Leiden: Brill.

Hogg, I.D., Larose, C., Lafontaine, Y. \& Doe, K.G., 1998. Genetic evidence for a Hyalella species complex within the Great Lakes-St. Lawrence River drainage basin: implications for ecotoxicology and conservation biology. Canadian fournal of Zoology, 76, 1134-1140.

Karaman, G.S., 1982. The family Gammaridae. In The Amphipoda of the Mediterranean (ed. S. Ruffo), pp. 245-364. Monaco: Mémoires de l'Institut Océanographique 13.

Karaman, G.S. \& Pinkster, S., 1977. Freshwater Gammarus species from Europe, North Africa and adjacent regions of Asia (Crustacea-Amphipoda). Part I. Gammarus pulex-group and related species. Bijdragen tot de Dierkunde, 47, 1-97.

Kolding, S., 1986. Interspecific competition for mates and habitat selection in five species of Gammarus (Amphipoda: Crustacea). Marine Biology, 91, 491-495.

Lincoln, R.J., 1979. British marine Amphipoda: Gammaridea. London: British Museum (Natural History).

Marques, J.C., 1989. Amphipoda (Crustacea) bentónicos da costa portuguesa: estudo taxonómico, ecológico e biogeográfico. $\mathrm{PhD}$ thesis, Universidade de Coimbra, Coimbra, Portugal.

Meyran, J.C., Monnerot, M. \& Taberlet, P., 1997. Taxonomic status and phylogenetic relationship of some species of the genus Gammarus (Crustacea, Amphipoda) deduced from mitochondrial DNA sequences. Molecular Phylogenetics and Evolution, 8, 1-10.

Pinkster, S., 1983. The value of morphological characters in the taxonomy of Gammarus. Beaufortia, 33, 15-28.

Skadsheim, A. \& Siegismund, H.R., 1986. Genetic relationships among north-western European Gammaridea (Amphipoda). Crustaceana, 51, 163-175.

Stock, J.H., 1967. A revision of the European species of the Gammarus locusta group (Crustacea, Amphipoda). Zoologische Verhandelingen, 90, 1-56.

Tseng, C., Ting, E., Johnson, D., Saluta, M. \& Dunst, R., 2001. Use of RAPD fingerprinting for differentiating E. coli isolates from human and animal sources. Life Science Newes, 7, 1-2.

Westheide, W. \& Hass-Cordes, E., 2001. Molecular taxonomy: description of a cryptic Petitia species (Polychaeta: Sylidae) from the island of Mahé (Seychelles, Indian Ocean) using RAPD markers and IST2 sequences. Fournal of Zoological Systematics and Evolutionary Research, 39, 103-111.

Witt, J.D.S. \& Hebert, P.D.N., 2000. Cryptic species diversity in the amphipod genus Hyalella within central glaciated North America: a molecular phylogenetic approach. Canadian fournal of Fisheries and Aquatic Sciences, 57, 687-698.

Submitted 2 February 2003. Accepted 21 November 2003. 